\title{
Textile industries between reality and ambition and prospects for modernization and development
}

\section{Opinion}

The textile industry is one of the oldest industries known to mankind. Many scientists believe that Syria and Mesopotamia are the first home of the textile industry.

Dressing is one of the three main necessities of man as well as food and shelter from the beginning of creation to the present day. Hence the importance of research and development in the textile industry.

The Syrian capital Damascus is famous for the textile industry and Syrian textile products have been known throughout the world as the Damask and Prokar fabrics, which are still famous today.

The industrial revolution began in Europe from the textile industries with the invention of the mechanical loom and the mechanical spinning machine, which later saw great developments in terms of automation. There is no machine except advanced programming and control, such as a jacquard machine.

The textile industry mainly concentrated in Damascus and Aleppo, and a smaller percentage in the rest of the governorates. Syrian cotton and Syrian textile products were exported to all countries of the world bearing the slogan "Made in Syria".

In the last third of the 20th century, many textile companies were created in Syria. The General Organization for Textile Industries was established in 1974 and became the supervisor of 28 companies. Textile companies produce the following commodities:

a. $100 \%$ Cotton yarnsof all types, including the turbocharged, turbocharged and turbocharged

b. Mixed yarn cotton polyester, viscose cotton

c. 100woolen yarns \%and woven.

d. Cotton fabrics are dyed, dyed and printed.

e. $100 \%$ Mystic carpet.

f. Underwear, ready-made garments and socks. In addition to cotton and medical gauze.

The number of workers in the public textile sector in Syria exceeds 30,000 workers, and this number is doubled in private and joint companies.

Unfortunately, the unjust global war on our country, Syria, destroyed most of these companies. After eight years of war, Syria has begun to recover and achieve victory. It will rebuild the old textile industry better than it did, and how can it not? Syria is known as "Syria Silk Road".

The tasks of the textile sector meet the needs of citizens and other government sectors, in addition to the well-known social tasks of labor employment.

The last half of the 1990s witnessed the beginning of a global crisis, during which consumption rates and growth declined steadily, accompanied by a decline in real incomes of consumers in many

\author{
Volume 4 Issue 4 - 2018
}

\section{Taher Rajab Kaddar}

Department of Textile Industries Mechanical Engineering and Their Techniques, Damascus University, Syrian Arab Republic

\begin{abstract}
Correspondence: Prof. Taher Rajab Kaddar, Department of Textile Industries Mechanical Engineering and Their Techniques, Faculty of Mechanical and Electrical Engineering, Damascus University, Syrian Arab Republic, Email dr.t-kadd@mail.sy
\end{abstract}

Received: June 12, 2018| Published: July 20, 2018

countries. Production has outstripped consumption and large quantities of it have been consumed by producers. These data coincided with a sharp increase in production of yarn and a large shift in manufacturing of synthetic products as a result of changing fashion trends on the one hand and lower prices on the other hand compared to cotton prices. Fashion greatly influences trends throughout the textile industry. Hence, an early understanding of local fashion trends helps to adopt the best planning and execution processes for the textile industry.

\section{Prospects for the development of textile industry}

Natural fibers of all kinds are strategic sources of fiber. Where cotton is an important strategic crop in many countries, including Syria, the cotton production in Syria in 2011 about one million tons of cotton beloved gives 320 thousand tons of cotton fabricated locally and exported a large part of it to various countries in the world, especially the European, before the war Cosmic on Syria. But it has fallen dramatically because of the war on terror, which Syria is facing on behalf of the world. The industrial fiber industry also plays an important role in this industry.

The development of the textile industry can only be integrated because most types and stages of production depend on each other, from the preparation of different fibers, composite materials, spinning, weaving, knitting, non-woven, dyeing and printing.

The textile industries sector is still past and present and will remain the most important and most profitable industries. The cycle of recovery of the investment capital is in Luxor compared to other industries. So we recommend investing in this important area.

The success of textile industries requires a number of basic procedures:

i. Emphasis on the use of high quality textile raw materials because their specifications will be inherited for the rest of the textile products to be manufactured from them.

ii. Development of schools and institutes of spinning and weaving, vocational rehabilitation centers and sections and colleges of textile industries through the provision of sufficient teaching cadres and qualified well. 
iii. Establish information centers that provide services to manufacturers, including: global statistics, target markets, competitors, product and manufacturer awareness, and ongoing media campaigns.

iv. The establishment of marketing centers supported by qualified cadres to carry out the marketing of products to reach the consumer directly.

v. Raise the quality of professional and administrative performance in cooperation with the global centers.

vi. Application of quality management systems in textile establishments in accordance with international standards to maintain the reputation of the textile products of the country concerned.

The textile industry has found itself in the face of stiff competition with trade liberalization from 1995, and protection barriers, as in some countries, could not be continued. This requires all concerned to prepare for risk and minimize losses if they are not able to participate in profits.

The development of textile industries in any country requires the development of a comprehensive plan to secure the raw materials needed for them (fibers, yarns, fabrics and accessories), qualified manpower, appropriate infrastructure, modern production lines, and modern marketing methods. Focus on the garment industry and ensure its requirements as it achieves the greatest value added and attracts the largest number of labor, which contributes to the strengthening of the national economy and the development of the society of any country.

Focus on the production of products, machinery and emerging textile technologies such as technical, smart, nanotechnology and other fabrics. In addition, there is a need to open up new horizons for the textile industries of the future, and this requires answering the question: What does the population of other planets need in the future of textile products?

\section{Acknowledgements}

None.

\section{Conflict of interest}

Author declares there is no conflict of interest in publishing the article. 